\title{
THE EFFECT OF ACUTE HYPOVOLEMIA ON THE RELEASE OF “ALDOSTERONE” AND ON THE RENAL EXCRETION OF SODIUM ${ }^{1}$
}

\author{
By DANIEL FINE,2 LEONARD E. MEISELAS, AND THERESA AUERBACH \\ (From the Medical Research Laboratories and the Department of Medicine, Maimonides Hos- \\ pital of Brooklyn, and the State University of New York College of Medicine at \\ New York City, N. Y.)
}

(Submitted for publication June 6, 1957; accepted October 17, 1957)

Automatic control of the volume of the body fluids, involving adjustment of the renal excretion of electrolytes and water, has been the subject of much recent study. Accumulating evidence suggests that a variety of functions of the extracellular fluid volume are significant determinants of the renal excretion of sodium (2). Some investigators have emphasized the role of "effective" blood volume (or a related parameter) as such a function (3-6), but the precise stimuli involved and the mode of their transmission to the kidney remain incompletely understood.

The recent demonstration that aldosterone, a natural salt-retaining steroid of the adrenal cortex $(7)$, is released in health and disease in quantities which are correlated with alterations in sodium excretion (8) and which are competent to influence the reabsorption of sodium by the renal tubules $(8,9)$ lends support to the long-held view that such an adrenal secretion is an important element in the normal government of body sodium (3, 10-12). Other investigations have shown that, in fact, the effect of changes in body fluid volume upon the renal excretion of sodium may be mediated in part by a graded secretion of aldosterone by the adrenal cortex (13-16).

The investigation reported here represents an attempt to define further certain aspects of the homeostatic reflexes involved in these processes in active humans, by an examination of the nature of some of the stimuli initiated by acute blood loss with its subsequent effect on the possible role of serum electrolytes and of aldosterone in the transmission of these stimuli and the mechanism of response of the end-organ effector, the kidney.

1 A preliminary report of these studies has appeared, in part, elsewhere (1).

2 Present address : Russelton Medical Group, Russelton, Pennsylvania.

\section{METHODS}

\section{Experimental plan}

Studies were performed upon two normally active, healthy humans (D. F., male, age 32; T. A., female, age 32 ), in whom unusual circulatory adjustments and losses of fluid via the skin were minimized by the proscription of strenuous exercise and the performance of studies during cool weather (October, 1955 to April, 1956). Observation on the female subject was made only during the first portion of the menstrual cycle.

A constant daily oral intake of food and fluid, supplemented by fixed amounts of sodium chloride, was begun prior to any observations and was maintained during the course of each study.

Each 24 hour study day commenced at 9 A.M. in the fasting state. Following three or more days of control observations, at 9 A.M. of each study day blood was removed by phlebotomy within an average of 20 minutes with the subject supine. In some instances, this was followed by a specific intravenous infusion (vide infra). Immediately thereafter, normal activity was resumed without significant symptoms and observations were continued for the ensuing four to five days. Following this, the experiment was ended and the blood previously removed was reinfused.

The studies were divided into three groups in accord with the basic procedure performed:

Group I-Simple phlebotomy. Four hundred fifty to $670 \mathrm{ml}$. of whole blood were removed by phlebotomy. Three studies were performed on each subject (D. F.-A, B, C; T. A.-a, b, c). In an attempt to eliminate any differences between these studies and those in Group II, arising solely from the effect of the sodium (14 to 20 mEq.) contained in the 25 per cent albumin infusions used in Group II, a similar amount of sodium (in normal saline) was infused following phlebotomy in a few of the Group I studies (I-A, I-B, I-b).

Group II-Phlebotomy plus 25 per cent albumin. Four hundred seventy-five to $660 \mathrm{ml}$. of whole blood were removed by phlebotomy. The intravenous infusion of a 25 per cent solution of salt-poor human albumin ${ }^{3}$ was begun immediately thereafter and was completed within

3 The albumin solutions employed in these studies were generously provided by the New York Regional Blood Program of the American Red Cross. 
20 minutes following phlebotomy. The amount of albumin employed was expected to produce an expansion of the plasma volume equal to the volume of whole blood withdrawn by phlebotomy, based upon the assumption that on the average one gram of injected albumin will draw $18 \mathrm{ml}$. of extravascular fluid into the circulation (17). Two studies were performed on each subject (D. F.-A, B ; T. A. -a, b).

Group III-Phlebotomy plus 25 per cent albumin plus saline. Following a $590 \mathrm{ml}$. phlebotomy, a 25 per cent solution of albumin and a normal solution of saline were infused intravenously over a 50 minute period. The quantity of albumin infused was determined as in Group II. The volume of saline solution plus the volume of albumin solution equalled the volume of blood withdrawn by phlebotomy. One study was performed on Subject D. F.

\section{Measurements}

Fasting body weight was determined periodically by weighing the subject in the same clothes after the 9 A.M. voiding. At appropriate intervals, venous blood was withdrawn without stasis and measurements were made of hemoglobin concentration (18) and hematocrit (19), and of the concentration of sodium, potassium and creatinine chromogen $(20)$ in the serum. Fasting blood for electrolyte determinations was obtained under oil. Urine was refrigerated during collection, and, after measurement of the 24 hour volume, aliquots were set aside for the determination of creatinine chromogen (20), sodium and potassium. The remainder was preserved at $-20^{\circ} \mathrm{C}$., for later measurement of 17-hydroxycorticosteroids (21), 17-ketosteroids (22), and for bioassay of salt-retaining activity. Saliva collections were obtained before 9 A.M. in the fasting state (23) for the measurement of sodium and potassium concentration. For Subject D. F., some direct assessment of the average daily fecal electrolyte excretion was obtained by analysis of incinerated aliquots of a homogenized five and six day pooled specimen, collected during two separate studies. The content of sodium, potassium and water in each constant diet was determined by analysis of aliquots of a homogenized duplicate 24 hour diet. All sodium and potassium determinations were made on a flame photometer using an internal Lithium standard.

Bioassay of salt-retaining activity of urine, based upon the effect of injected extracts upon the urinary potassium : sodium ratio of adrenalectomized rats, was performed by modification of the method of Johnson (24).4 Extracts were prepared by the method of Axelrad, Cates, Johnson, and Luetscher (25) (using hydrolysis A and B combined), but without chromatographic partition. The results are referred to as "aldosterone" and expressed as gamma DCA equivalents (GDE), since true aldosterone was not actually measured. However, the results of as-

4 The desoxycorticosterone acetate (DCA) employed as a standard in this assay was kindly provided by the Schering Corporation, Charles Pfizer and Company, and the Ciba Pharmaceutical Company. say of unchromatographed extracts do not usually diverge markedly from those of assay of "fraction E" (25). Since the 17-hydroxycorticosteroids were never abnormally elevated in these urines, the possibility of interfering effects was probably lessened (24). A control and postphlebotomy urine from the same study were always extracted and assayed simultaneously. The postphlebotomy urinary "aldosterone" excretion was considered to be significantly elevated if it exceeded the normal range of control values for all studies in that subject (i.e., mean of all controls for that subject plus or minus two times S. D.) and if the "aldosterone" effect of the postphlebotomy urine extract and of the paired control urine extract differed significantly in the bioassay (i.e., if $p<0.05$ for the difference of means of the potassium: sodium ratios of the rat urines in the bioassay of each extract).

\section{Calculations}

The average glomerular filtration rate over a 24 hour period was estimated by the endogenous creatinine chromogen clearance (26), calculated from the total chromogen excretion and the mean of creatinine chromogen concentrations of three to four serum specimens obtained during this period.

Each 24 hour urine volume was used as an estimate of daily water excretion.

A crude assessment of changes in plasma and blood volume associated with phlebotomy was obtained as follows:

$$
\begin{aligned}
\mathrm{BV}_{0} & =73 \times \mathrm{BW}(27) \\
\mathrm{BV}_{1} & =\mathrm{BV}_{0}-\mathrm{V} \\
\mathrm{BV}_{\mathrm{n}} & =\mathrm{BV}_{1} \times \frac{\mathrm{Hb}_{1}}{\mathrm{Hb}_{\mathbf{n}}} \\
\Delta \mathrm{BV}_{\mathbf{n}} & =\mathrm{BV}_{\mathrm{n}}-\mathrm{BV}_{0} \\
\mathrm{PV}_{\mathrm{n}} & =\mathrm{BV}_{\mathrm{n}} \times\left(1-\mathrm{Ht}_{\mathbf{n}}\right) \\
\Delta \mathrm{PV}_{\mathrm{n}} & =\mathrm{PV}_{\mathrm{n}}-\mathrm{PV}_{0}
\end{aligned}
$$

where $\mathrm{V}$ is the volume of blood removed at phlebotomy (ml.), BV is the total blood volume (ml.), PV is the total plasma volume (ml.), $\mathrm{Hb}$ is the hemoglobin concentration (grams per cent), $\mathrm{Ht}$ is the hematocrit per 100, BW is the body weight (kilograms), $\Delta$ is the change from prephlebotomy value, and where subscript 0 is the value immediately before phlebotomy, subscript 1 is the value immediately after, and subscript $\mathbf{n}$ is the value at specific time after completion of phlebotomy.

Because complete balances were not determined, variations in daily renal excretion are presented as deviations (plus or minus) from the mean of the daily urinary excretion during the control period in each study. Since a 24 hour excretion rate, which was less than the mean control rate, represented the amount retained over and above the mean control, it is referred to as "renal conservation." When the excretion rate exceeded the mean control value, it is referred to as "renal loss." The effect of the phlebotomy procedure upon the excretion 


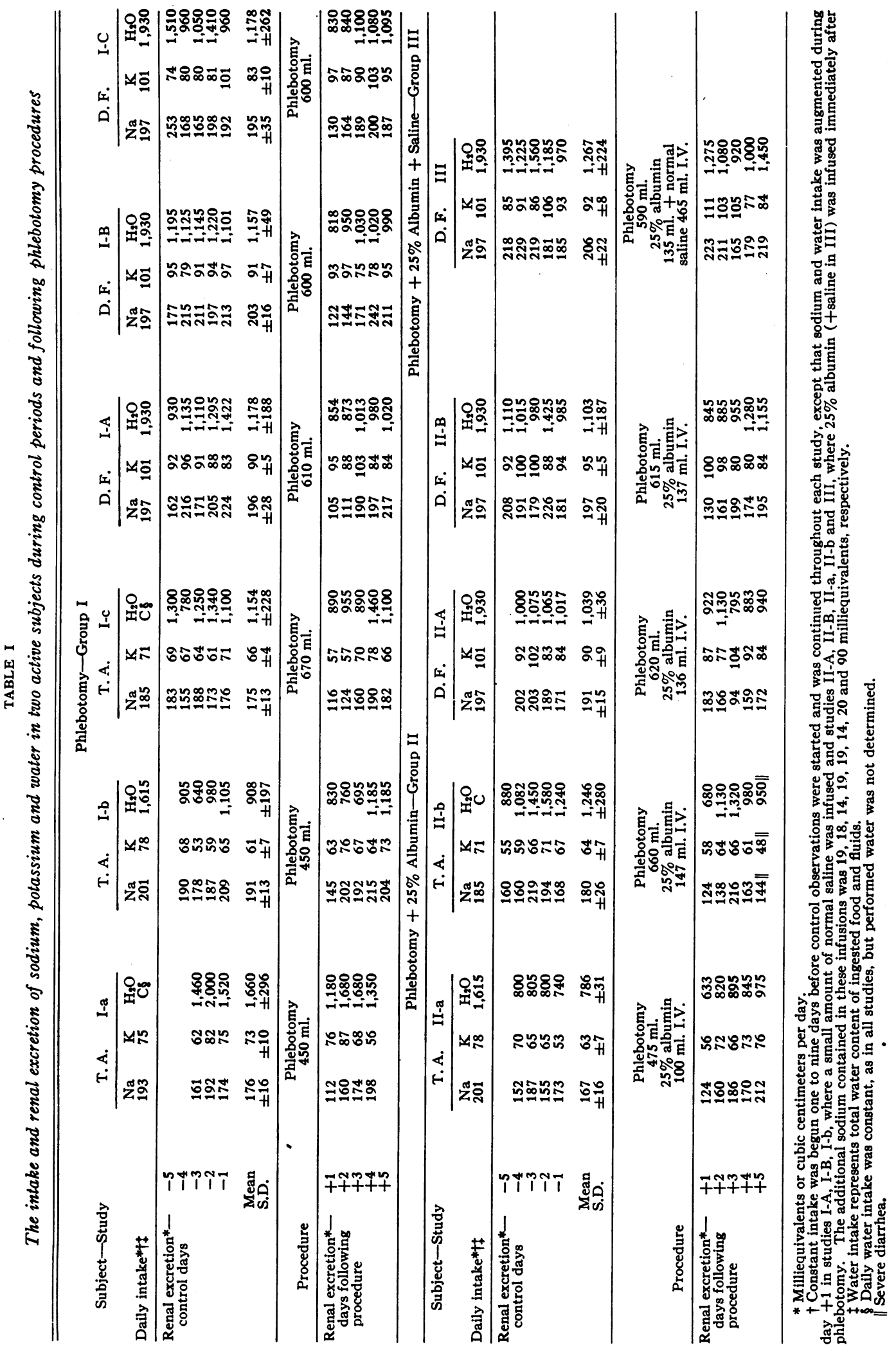


of sodium, potassium and water is estimated by the cumulative "conservation" or "loss" of these substances during the consecutive days, immediately following phlebotomy, in which the excretion rate deviated from the mean control value in a consistently positive or negative direction.

A rough assessment of balance during the control periods is made on the basis of the assumption that in Subject D. F. the average daily fecal sodium and potassium equalled the mean of that in the two pooled specimens (sodium equals $0.4 \mathrm{mEq}$. per day, and potassium equals $6 \mathrm{mEq}$. per day) and that in Subject T. A. the daily fecal sodium and potassium corresponded to the range found in human subjects on a variety of diets (sodium equals $4 \pm 4 \mathrm{mEq}$. per day, and potassium equals
$10 \pm 5 \mathrm{mEq}$. per day) (28). All stools were formed except on the final day of one study (II-b).

\section{RESULTS}

Group I-Simple phlebotomy (Table I and Figure 1)

Blood volume. Hemodilution occurred to only a limited extent by eight hours, but essentially restored prephlebotomy blood volume by 24 to 48 hours after the phlebotomy (mean deviation from prephlebotomy blood volume was $-120 \mathrm{ml}$. at 24 hours and $-40 \mathrm{ml}$. at 48 hours). That the ex-

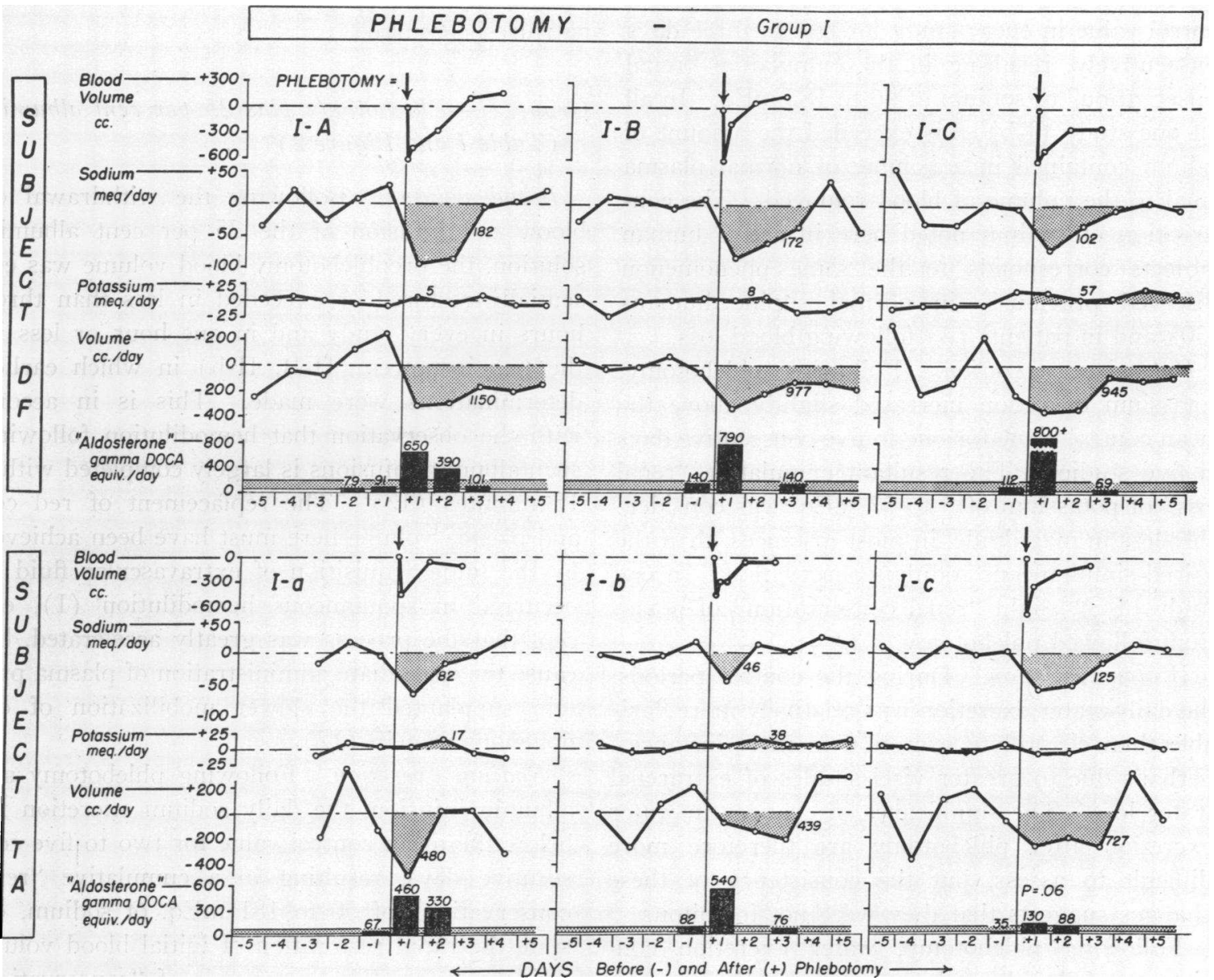

Fig. 1. The Effect of Simple Phlebotomy on Blood Volume, Urine Volume and Urinary Sodium, Potassium, AND "Aldosterone"

Blood volume is depicted as the deviation from assumed prephlebotomy value. Urinary volume, sodium and potassium are depicted as deviations from the mean prephlebotomy control value for each study and shaded areas with adjacent figures represent cumulative "renal conservation" of sodium and water and cumulative "renal loss" of potassium following phlebotomy. Urinary "aldosterone" rise after phlebotomy which did not differ significantly from prephlebotomy value is indicated by $\mathrm{p}<0.05$. Horizontal shaded area indicates mean of all control "aldosterone" values plus or minus two times S. D. for each subject. 
pansion of plasma volume in response to blood loss can account for the replacement of red blood cell volume as well as plasma volume has been noted previously (29) and suggests that regulation of plasma volume is subservient to the restoration of total blood volume, rather than to the maintenance of plasma volume alone. The necessary expansion of plasma volume is attained under these circumstances by the acquisition of fluid from extravascular sources, induced by the oncotic effect of plasma protein derived from endogenous stores (29).

Sodium excretion. Following phlebotomy, renal sodium excretion was reduced below the mean control value in every study for one to three days consecutively, resulting in the cumulative "renal conservation" of sodium of 46 to $182 \mathrm{mEq}$. In all but one study (I-b), this exceeded the amount of sodium contained in a volume of normal plasma equal to the volume of blood removed. The conservation of sodium noted here in active human subjects corresponds to the same phenomenon observed previously in normal supine humans (30) and in patients (4) following blood loss.

Potassium excretion. Following phlebotomy, potassium excretion increased slightly above the mean control value for one to five consecutive days in five studies. The resultant cumulative "renal loss" of potassium of 5 to $57 \mathrm{mEq}$. was considerably less in magnitude, in most instances, than the paired simultaneous sodium conservation. In one study (I-c), slight "renal conservation" of potassium followed phlebotomy.

Water excretion. During the control periods, the daily water excretion was relatively more variable than electrolyte excretion in most instances, perhaps due to greater viscissitudes of extrarenal water loss. The significance of changes in water excretion after phlebotomy are therefore more difficult to assess, but the consistency of these changes suggests that they were not fortuitous.

Following phlebotomy, water excretion consistently fell below the mean control excretion (although not below the mean minus two times S. D.) for one to five consecutive days, resulting in cumulative "renal conservation" of water of 439 to $1,150 \mathrm{ml}$. during this period. This volume was approximately equal to or greater than the volume of the phlebotomy in each instance.

"Aldosterone." The normal range of the con- trol urinary "aldosterone" was $50 \pm 40 \mathrm{GDE}$ per 24 hours for all studies in Subject T. A., and 110 $\pm 80 \mathrm{GDE}$ per 24 hours for all studies in Subject D. F. During the first 24 hours after phlebotomy, urinary "aldosterone" rose significantly above the prephlebotomy control value in five studies to levels of 460 to 800 plus GDE per 24 hours. Where it was measured, the urinary "aldosterone" was elevated on the second day (I-A, I-a) and returned to the normal control range on the third day (I-A, I-B, I-C, I-b). In the one study (I-c) in which the postphlebotomy "aldosterone" rise was not considered to be significant, the largest phlebotomy was performed and a marked antinatriuresis occurred.

\section{Group II-Phlebotomy plus 25 per cent albumin (Table I and Figure 2)}

Blood volume. Following the withdrawal of blood and infusion of the 25 per cent albumin solution, the prephlebotomy blood volume was essentially restored or exceeded in less than three hours in every study and in one hour or less in the two instances (II-B, II-b) in which earlier determinations were made. This is in accord with the observation that hemodilution following such albumin infusions is largely completed within 15 minutes (17). The replacement of red cell and plasma volume here must have been achieved by the same acquisition of extravascular fluid as occurred in spontaneous hemodilution (I), except that the process was greatly accelerated, because the immediate administration of plasma protein supplanted the slower mobilization of endogenous protein (17).

Sodium excretion. Following phlebotomy and albumin infusion, the daily sodium excretion fell below the mean control value for two to five consecutive days, resulting in a cumulative "renal conservation" of 50 to $181 \mathrm{mEq}$. of sodium, despite the rapid restoration of initial blood volume (vide supra). The magnitude of "conservation" approximated that following simple phlebotomy (I), but the pattern of antinatriuresis was less consistent. In three studies (II-B, II-a, II-b) the lowest sodium excretion occurred during the first day, although the sodium intake on that day exceeded the constant intake of other days, due to the sodium content (14 to $20 \mathrm{mEq}$.) of the infused 
25 per cent albumin solution. However, in one study (II-A) the maximum antinatriuresis occurred after the first 48 hours, despite the restoration of blood volume by two and one-half hours after venisection.

Potassium excretion. Following phlebotomy and albumin infusion, there was no consistent or significant change in potassium excretion.

Water excretion. During the control periods, water excretion was again somewhat variable. Following phlebotomy and albumin infusion, water excretion was reduced below the mean control value in every instance for one to three consecutive days, resulting in a cumulative "renal conservation" of water of 117 to $682 \mathrm{ml}$.

"Aldosterone." Following phlebotomy and al- bumin infusion, the urinary "aldosterone" rose above the control range for each subject in association with the maximum antinatriuresis, although this rise was not considered to be significant in a study (II-b) in which the largest phlebotomy was performed and in which a marked antinatriuresis occurred. In each subject, the significant elevations were more modest than after simple phlebotomy (I), although this difference may not be meaningful.

\section{Group III-Phlebotomy plus 25 per cent albumin} plus saline (Table I and Figure 2)

Following phlebotomy and infusion of the albumin and saline solutions, blood volume was found to surpass the prephlebotomy value at the

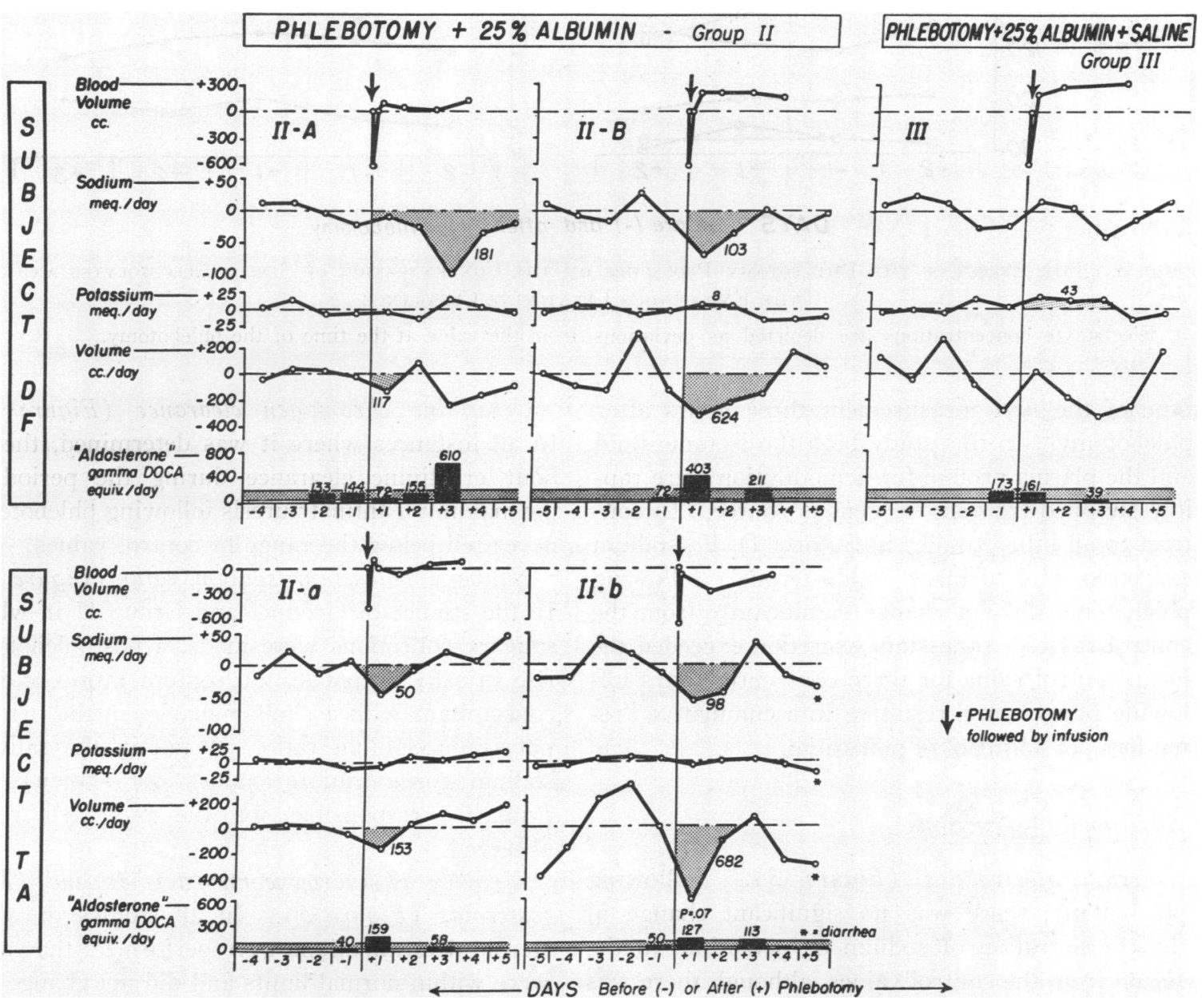

Fig. 2. The Effect of Phlebotomy Plus 25 Per Cent Albumin Infusion (Plus or Minus Saline Infusion) on Blood Volume, Urine Volume, and Urinary Sodium, Potassium, and "Aldosterone" Graphic representation as in Figure 1. 


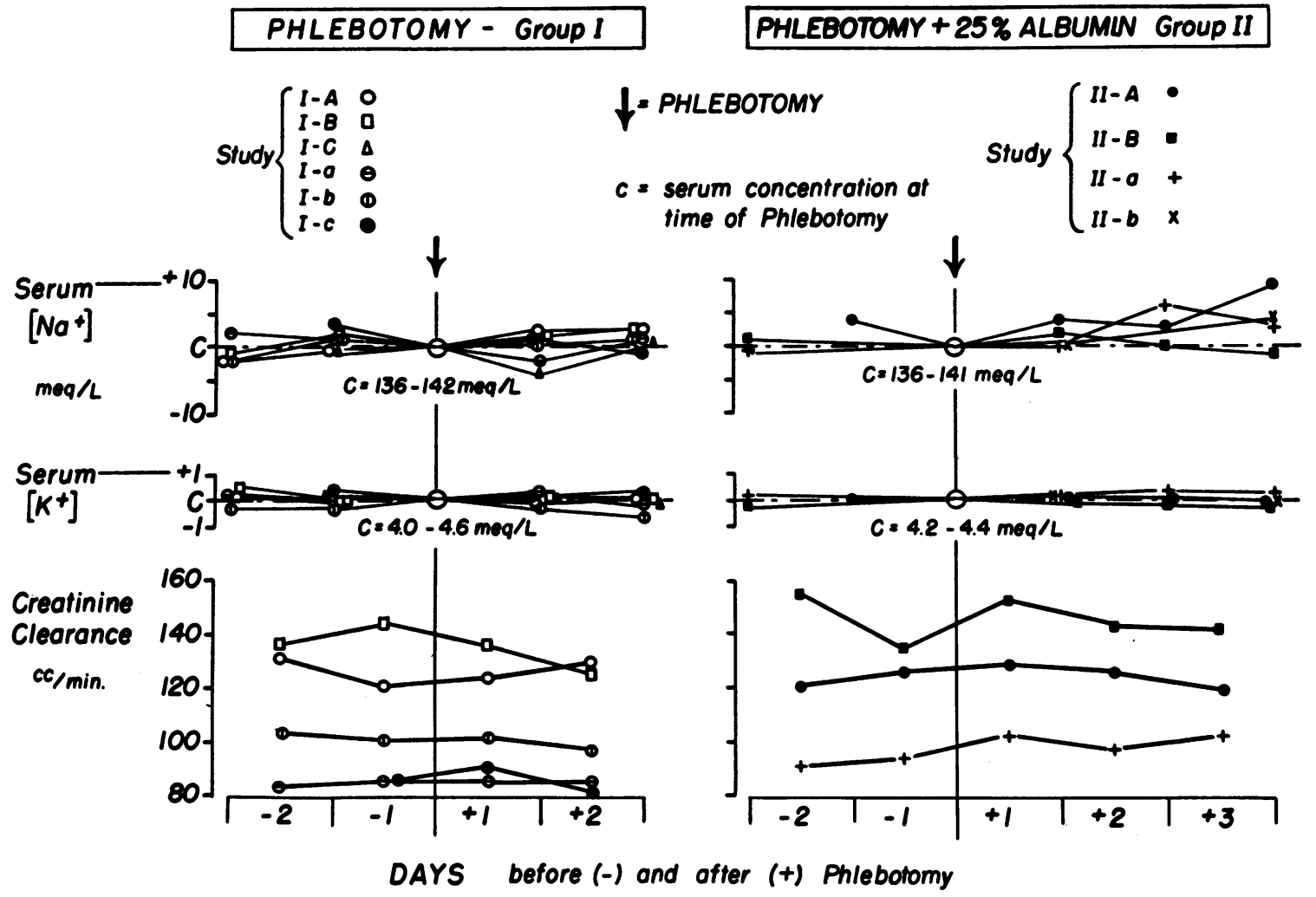

Fig. 3. The Effect of the Phlebotomy Procedure on the Concentration of Serum Electrolytes and on the Endogenous Creatinine Clearance

Electrolyte concentrations are depicted as deviations from the value at the time of the phlebotomy.

time of the first measurement three hours after phlebotomy. In this study both the isotonic fluid and the plasma protein for hemodilution were rapidly supplied from an exogenous source. In contrast to all other studies in Subject D. F., sodium excretion and urinary "aldosterone" following phlebotomy did not change significantly from the control values. Potassium excretion exceeded the mean control value for three consecutive days following phlebotomy, resulting in a cumulative "renal loss" of $43 \mathrm{mEq}$. of potassium.

\section{Additional observations}

Serum electrolytes (Figure 3). Following phlebotomy, there was no significant change in the concentration of sodium or potassium in the serum from the control values, although there was a tendency for the sodium concentration to rise slightly following the phlebotomy and albumin infusion (II).
Creatinine chromogen clearance (Figure 3). In all instances where it was determined, the 24 hour creatinine clearance during the period of the maximum antinatriuresis following phlebotomy never fell below the range of control values.

Salivary potassium: sodium ratio (Figure 4). In the studies of Group I and Group II in which salivary collections were made, a postphlebotomy rise in salivary potassium: sodium ratio occurred concomitant with a similar change in the urinary potassium: sodium ratio. A fall in the salivary sodium concentration (values not shown) was primarily responsible for the increased ratios observed.

Urinary 17-hydroxycorticosteroids and 17-ketosteroids (Figure 5). In all studies in which steroid determinations were performed, the values were within normal limits and did not change significantly in association with the "aldosterone" increases.

Electrolyte balance during control periods. 
Based upon the assumptions discussed under the Methods section, the mean daily balance of sodium and potassium during the control period of all studies varied from slightly negative to moderately positive.

Body weight. During the entire period in which these studies were performed, Subject D. F. weighed 73.6 to 76.4 kilograms and Subject T. A. weighed 52.0 to 54.6 kilograms. The greatest change in weight during any one study was 0.8 kilogram. Therefore, excluding gross variations in water balance, it may be assumed that major changes in body composition did not occur during these experiments.

\section{DISCUSSION}

An acute reduction in the volume of the blood clearly initiated processes which culminated in a moderate conservation of sodium and water by the kidney, a less intense and less consistent augmentation of potassium excretion and a fairly consistent elevation of urinary "aldosterone."

Our data support the concept that these alterations in the excretion of electrolytes can be attributed predominantly to modification of renal tubular function $(4,30)$ rather than to alteration of the loads of these electrolytes filtered at the glomerulus, since there were no significant alterations of the concentrations of sodium and potassium in the serum or of the endogenous creatinine chromogen clearances following phlebotomy. The view that the fairly consistent relationship between the increased "aldosterone" and the modified electrolyte excretion was causal, rather than

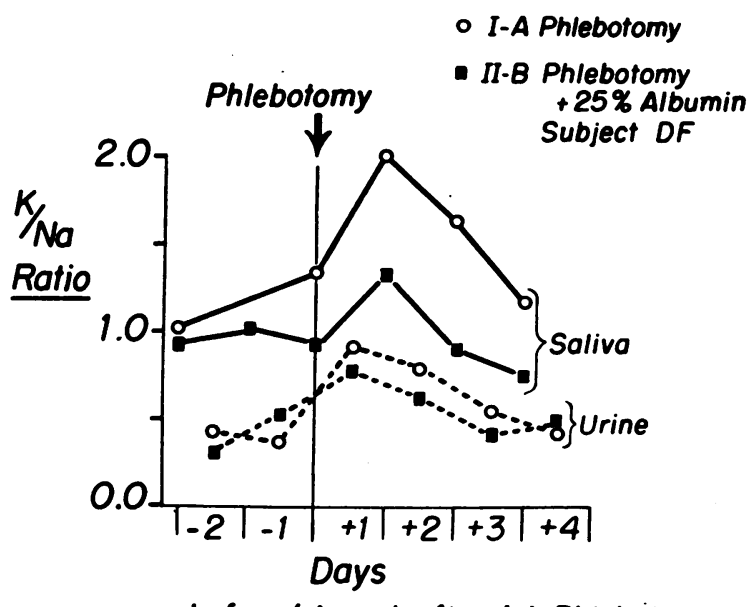

before (-) and after (+) Phlebotomy

Fig. 4. The Relationship of the Potassium: Sodium Ratio in Saliva to That in Urine Before and After Phlebotomy

merely coincident, is supported by a consideration of the quantitative aspects of these responses. It seems reasonable to assume that here, as in other studies $(8,14,15)$, urinary "aldosterone" reflected the level of circulating aldosterone. The elevated quantities of "aldosterone" found following the removal of blood in most of our Group I studies were roughly of the same order of magnitude as the amounts recovered from the urine of human subjects, with and without adrenal insufficiency, following the administration of 600 to 1,250 gamma of aldosterone per day $(8,31)$ [assuming that aldosterone is between 30 and 40 times as potent as DCA in the bioassay (8)]. The exhibition of such quantities of aldosterone

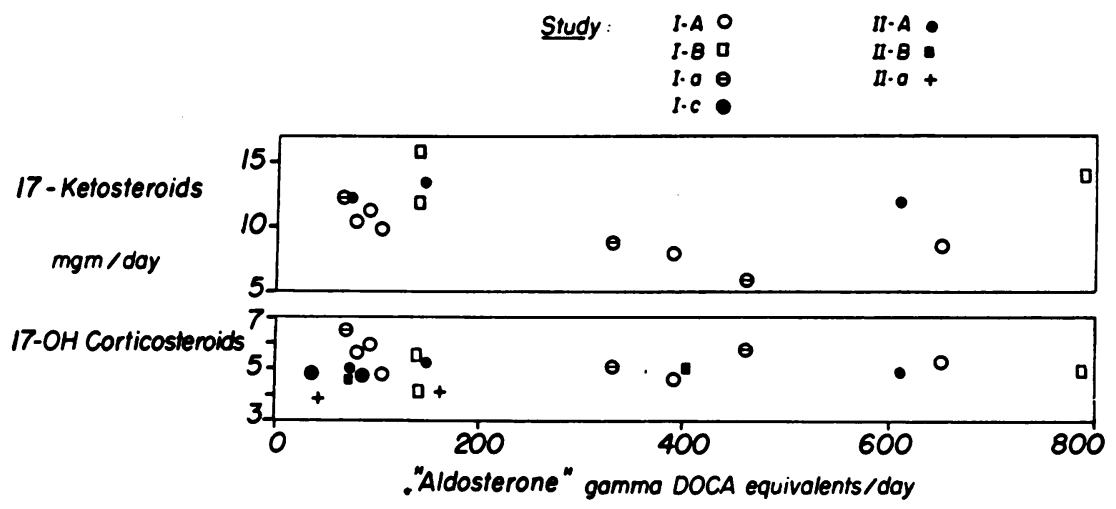

Fig. 5. The Relationship OF URinary 17-Ketosteroids and 17-HydroxycorticosTEROIDS to URINARY "AlDOSTERONE" 
to humans, without adrenal insufficiency, results in a moderate decrement in sodium excretion and a generally lesser or absent increment in potassium excretion by the kidney (31-33), which approximates the dimensions and configuration of the renal response in our subjects following simple phlebotomy (1). Additional support for the assumption that the elevation of urinary "Aldosterone" reflected a significant rise in circulating aldosterone is provided by the pari passu rise in the potassium: sodium ratio in the salivary secretion, a function which has been observed to respond in such a fashion to exogenously administered aldosterone (7). Although significant elevations of urinary "aldosterone" in studies of Group II tended to be of a smaller magnitude than in those of Group I, it seems reasonable to assume that they also indicated an increased circulating level.

The marked renal conservation of sodium associated with the largest phlebotomies in Subject T. A. (I-c, II-b) in the absence of a large or significant elevation of the urinary "aldosterone" is not explained by the mechanisms considered above. In study I-c the data do not suggest a fall in the glomerular filtration rate which could produce a discordance between urinary and circulating steroids (34). In all of these studies, reductions in the glomerular filtration rate may have occurred which were too small to detect by the method employed and which could have been responsible for significant sodium retention by the kidney (35). In addition, reduction of blood volume and its sequelae may, like other stimuli, accelerate the tubular reabsorption of sodium independently of variations in salt-retaining steroid (36).

The water conservation observed following simple phlebotomy (1) also appears to have stemmed primarily from an enhanced tubular reabsorption of water, as indicated by the stable creatinine clearances. Our experiments do not provide data to suggest whether this effect was mediated by antidiuretic hormone $(\mathrm{ADH})$ or by mechanisms which operate independently of this hormone (37). A competent stimulus for the release of $\mathrm{ADH}$ was present as some function of decreased fluid volume (38), and may have been present as a rising tonicity (39) resulting from the primary conservation of sodium, although the latter may have been obscured by secondary water retention.

The rise in "aldosterone" noted in our studies, without a concurrent rise in other urinary corticosteroids, resembles the dissociation seen in many situations where an intense stimulus for sodium conservation exists (40). The observation that blood loss in the dog produces an increase in the aldosterone in adrenal venous blood, which is greater proportionately than the increase in hydrocortisone (41), suggests that the increased urinary "aldosterone" noted in our studies was due to augmented adrenal secretion of aldosterone, although our data do not exclude the possibility that it derived from a diminished rate of peripheral destruction. If such an increased secretion did in fact occur, it is unlikely that adrenocorticotropic hormone (ACTH) was the responsible stimulus, since this hormone produces a marked elevation of 17 -hydroxycorticosteroid release but exerts little effect upon the release of aldosterone $(7,40)$. It also is unlikely that an elevation of the serum potassium concentration or potassium: sodium ratio provided a stimulus for aldosterone release (42), since these parameters were not significantly altered following phlebotomy, although it is possible that small, transient changes were obliterated by secondary renal responses.

The nature of the primary stimuli which lead to an augmented aldosterone release and to an antinatriuresis is of considerable interest. The absence of sodium conservation when the removed blood was replaced with 25 per cent albumin and saline (Group III) suggests that neither the stress of the phlebotomy nor the loss of red blood cells per se provided an adequate stimulus. The response to simple phlebotomy (Group I), however, is compatible with the concept that a decrease in blood volume, pressure or flow in some area of the intravascular space can produce an effective stimulus $(3-6)$.

On the other hand, the retention of sodium and the "aldosterone" rise which occurred despite the rapid restoration of initial blood volume, when phlebotomy was followed by the infusion of a 25 per cent albumin solution (Group II), suggests that a sustained reduction of blood volume is not the exclusive stimulus. It seems unlikely that the evanescent reduction of blood volume which occurred here (II) was itself an effective 
stimulus, because it was of such short duration, because the major effector response did not occur until two days after the phlebotomy in one study (II-A), and since no such response appeared when blood volume was restored by the 25 per cent albumin-saline plasma substitute (III) over a comparable period. Since the initial reexpansion of blood volume must have been attained by the rapid uptake of an appropriate volume of essentially isotonic fluid from an extravascular locus, probably the interstitial space (43), it seems reasonable to conjecture that reduction of that space (or some function thereof) may provide a stimulus which is monitored by some suitable local receptors.

In view of the fact that hyperoncotic albumin infusions are in themselves antinatriuretic in normal and adrenal insufficient subjects (44), it is not certain that the mechanisms responsible for the sodium conservation observed when 25 per cent albumin infusions restored blood volume (II) were the same as those responsible for the sodium conservation noted after blood loss and spontaneous hemodilution (I). However, since an initial rise in oncotic pressure following 25 per cent albumin infusion must have been rapidly extinguished by the movement of fluid into the vascular compartment, it would seem less likely that the stimulus of a rising oncotic pressure was involved here, than the stimulus of a diminishing interstitial fluid volume (44).

The concept of a stimulus arising from a decrease in the interstitial volume is not incompatible with the fact that an aldosterone rise has been observed following blood removal, even when the plasma sodium and water removed were replaced by a normal saline infusion (9), since restoration of the total blood volume, not just of the plasma volume alone, is the dominant physiological desideratum in the hemodilution process (29) and would have required the accretion of additional isotonic fluid from extravascular sources to replace the red cell volume removed. Inferences drawn from a variety of other studies $(2,44,45)$ have suggested that a decrease in interstitial fluid volume in some area may be one of several initial stimuli for the renal conservation of sodium, regardless of how it is transmitted to the kidney.

In these studies, the effect of sodium lost in phlebotomy was not controlled by observing the effect of sodium replacement alone. Therefore, it cannot be concluded from our data that the sodium conservation after blood loss occurs by mechanisms which differ from those operative following the deprivation of dietary sodium (8). In both of these situations, the initial stimulus may be the absolute loss of body sodium or the simultaneous decrement of portions of the extracellular fluid volume.

\section{SUMMARY}

The effect of acute hypovolemia, induced by phlebotomy, was observed in two normal active human subjects maintained on constant diets.

When hemodilution occurred spontaneously, there was a consistent reduction of urinary sodium, associated with a fairly consistent elevation of urinary "aldosterone." Similar changes in sodium and "aldosterone" excretion prevailed when the blood volume was rapidly restored by the immediate infusion of 25 per cent salt-poor human albumin.

Following phlebotomy, there was no significant alteration in the endogenous creatinine chromogen clearance, the urinary 17-hydroxycorticosteroids and 17-ketosteroids, or in the concentration of sodium and potassium in the serum.

From these observations, it appears that blood loss and the associated hemodilution process initiate changes which may be monitored in the extravascular space as well as in the intravascular space, and which culminate in the renal conservation of sodium, probably due, in part, to the accelerated tubular reabsorption of this ion.

The renal response seems to be mediated, in part, by an increase in the effective level of circulating aldosterone, which does not depend upon ACTH or changes in the potassium: sodium ratio in the serum.

\section{ACKNOWLEDGMENTS}

We are deeply indebted to Dr. Norman Weissman for his invaluable advice and criticism. We also wish to thank Dr. Max Michael, Jr., for his criticisms; Mr. Gerald Dobkin for his technical advice; Dr. Martin Perlmutter and Mr. Marvin Numeroff for the determinations of urinary 17-ketosteroids and 17-hydroxycorticosteroids; Dr. Alvin Block for his help; and Mrs. Natalie Kochan and Miss Libby Tanzman for assistance in preparation of the manuscript. 


\section{REFERENCES}

1. Fine, D., Meiselas, L. E., and Auerbach, T. The relationship of acute reduction in blood volume to the release of "aldosterone." Clin. Res. Proc. 1956, 4, 126.

2. Grossman, J. Volume factors in body fluid regulation. Arch. intern. Med. 1957, 99, 93.

3. Peters, J. P. The role of sodium in the production of edema. New Engl. J. Med. 1948, 239, 353.

4. Borst, J. G. G. The maintenance of an adequate cardiac output by the regulation of the urinary excretion of water and sodium chloride; an essential factor in the genesis of oedema. Acta med. scand. 1948, Suppl. 207.

5. Wilkins, R. W., Tinsley, C. M., Culbertson, J. W., Burrows, B. A., Judson, W. E., and Burnett, C. H. The effects of venous congestion of the limbs upon renal clearances and the excretion of water and salt. I. Studies in normal subjects and in hypertensive patients before and after splanchnicectomy. J. clin. Invest. 1953, 32, 1101.

6. Epstein, F. H. Renal excretion of sodium and the concept of a volume receptor in Essays in Metabolism: The John Punnett Peters Number of the Yale Journal of Biology and Medicine, L. G. Welt, Ed. Boston, Little, Brown \& Co., 1957, pp. 282-298.

7. Simpson, S. A., and Tait, J. F. Recent progress in methods of isolation, chemistry, and physiology of aldosterone in Recent Progress in Hormone Research, G. Pincus, Ed. New York, Academic Press Inc., 1955, vol. II, pp. 183-210.

8. Luetscher, J. A., Jr., and Curtis, R. H. Observations on aldosterone in human urine. Fed. Proc. 1955, 14, 746.

9. Bartter, F. C. The role of aldosterone in normal homeostasis and in certain disease states. Metabolism 1956, 5, 369.

10. Loeb, R. F., Atchley, D. W., Benedict, E. M., and Leland, J. Electrolyte balance studies in adrenalectomized dogs with particular reference to the excretion of sodium. J. exp. Med. 1933, 57, 775.

11. Conn, J. W., Johnston, M. W., and Louis, L. H. Acclimatization to humid heat: A function of adrenal cortical activity (abstract). J. clin. Invest. 1946, 25, 912.

12. Leaf, A., and Couter, W. T. Evidence that renal sodium excretion by normal human subjects is regulated by adrenal cortical activity. J. clin. Invest. 1949, 28, 1067.

13. Beck, J. C., Dyrenfurth, I., Giroud, C., and Venning, E. $\mathrm{H}$. - Observations on the regulatory mechanisms of aldosterone secretion in man. Arch. intern. Med: 1955, 96, 463.

14. Duncan, L. E., Jr., Liddle, G. W., and Bartter, F. C. The effect of changes in body sodium on extracellular fluid volume and aldosterone and sodium excretion by normal and edematous men. J. clin. Invest. 1956, 35, 1299.
15. Bartter, F. C., Liddle, G. W., Duncan, L. E., Jr., Barber, J. K., and Delea, C. The regulation of aldosterone secretion in man: The role of fluid volume. J. clin. Invest. 1956, 35, 1306.

16. Muller, A. F., Riondel, A. M., and Mach, R. S. Control of aldosterone excretion by changes in volume of body-fluid. Lancet 1956, 1, 831.

17. Heyl, J. T., Gibson, J. G., 2nd, and Janeway, C. A. Studies on the plasma proteins. V. The effect of concentrated solutions of human and bovine serum albumin on blood volume after acute blood loss in man. J. clin. Invest. 1943, 22, 763.

18. Crosby, W. H., Munn, J. I., and Furth, F. W. Standardizing a method for clinical hemoglobinometry. U. S. armed Forces med. J. 1954, 5, 693.

19. Wintrobe, M. M. Macroscopic examination of the blood: Discussion of its value and description of the use of a single instrument for the determination of sedimentation rate, volume of packed red cells, leukocytes and platelets, and of icteric index. Amer. J. med. Sci. 1933, 185, 58.

20. Bonsnes, R. W., and Taussky, H. H. On the colorimetric determination of creatinine by the Jaffe reaction. J. biol. Chem. 1945, 158, 581.

21. Silber, R. H., and Porter, C. C. Determination of 17, 21-dihydroxy-20-ketosteroids in urine and plasma. J. biol. Chem. 1954, 210, 923.

22. Drekter, I. J., Pearson, S., Bartczak, E., and McGavack, T. H. Rapid method for determination of total urinary 17-ketosteroids. J. clin. Endocr. 1947, 7, 795.

23. Frawley, T. F., and Thorn, G. W. Relation of salivary sodium-potassium ratio to adrenal cortical activity in Proceedings of the Second Clinical ACTH Conference, vol. I., Research, J. R. Mote, Ed. Philadelphia, Blakiston, Co. 1951, pp. 115-122.

24. Johnson, B. B. Bioassay of adrenal cortical steroids on the basis of electrolyte excretion by rats: Effects of 11-desoxy and 11-oxy-steroids. Endocrinology 1954, 54, 196.

25. Axelrad, B. J., Cates, J. E., Johnson, B. B., and Luetscher, J. A., Jr. Aldosterone in urine of normal man and of patients with oedema: Its increased recovery after hydrolysis with acid and with beta-glucuronidase. Brit. med. J. 1955, 1, 196.

26. Sirota, J. H., Baldwin, D. S., and Villarreal, H. Diurnal variations of renal function in man. J. clin. Invest. 1950, 29, 187.

27. Berson, S. A. Blood volume in health and disease. Bull. N. Y. Acad. Med. 1954, 30, 750.

28. Danowski, T. S., and Greenman, L. Changes in fecal and serum constituents during ingestion of cation and anion exchangers. Ann. N. Y. Acad. Sci. 1953, 57, 273.

29. Ebert, R. V., Stead, E. A., Jr., and Gibson, J. G., II. Response of normal subjects to acute blood loss. Arch. intern. Med. 1941, 68, 578. 
30. Lombardo, T. A., Eisenberg, S., Oliver, B. B., Viar, W. N., Eddleman, F. E., Jr., and Harrison, T. R. Effects of bleeding on electrolyte excretion and on glomerular filtration. Circulation 1951, 3, 260.

31. Ward, L. E., Polley, H. F., Slocumb, C. H., Hench, P. S., Mason, H. L., Mattox, V. R., and Power, M. H. The effects of aldosterone (electrocortin) and of 9-alpha-fluorohydrocortisone acetate on rheumatoid arthritis: Preliminary report. Proc. Mayo Clin. 1954, 29, 649.

32. Mach, R. S., and Fabre, J. Clinical and metabolic effects of aldosterone in Ciba Foundation Colloquia on Endocrinology. The Human Adrenal Cortex, G. Wolstenholme and M. Cameron, Eds. Boston, Little, Brown \& Co., 1955, vol. VIII, pp. 361-372.

33. Thorn, G. W., Sheppard, R. H., Morse, W. I., Reddy, W. J., Beigelman, P. M., and Renold, A. E. Comparative action of aldosterone and 9-alphafluorohydrocortisone in man. Ann. N. Y. Acad. Sci. 1955, 61, 609.

34. Marks, L. J., and Leaf, A. The relationship of the renal excretion of adrenal corticoids to variations in renal hemodynamics. J. clin. Invest. 1953, 32, 813.

35. Selkurt, E. E. Sodium excretion by the mammalian kidney. Physiol. Rev. 1954, 34, 287.

36. Rosenbaum, J. D., Papper, S., and Ashley, M. M. Variations in renal excretion of sodium independent of change in adrenocortical hormone dosage in patients with Addison's disease. J. Clin. Endocr. 1955, 15, 1459.
37. Berliner, R. W., and Davidson, D. G. Production of hypertonic urine in the absence of pituitary antidiuretic hormone. J. clin. Invest. 1956, 35, 690.

38. Leaf, A., and Mamby, A. R. An antidiuretic mechanism not regulated by extracellular fluid tonicity. J. clin. Invest. 1952, 31, 60 .

39. Verney, E. B. Croonian lecture: The antidiuretic hormone and the factors which determine its release. Proc. roy. Soc. B 1947, 135, 25.

40. Liddle, G. W., Duncan, L. E., Jr., and Bartter, F. C. Dual mechanism regulating adrenocortical function in man. Amer. J. Med. 1956, 21, 380.

41. Farrell, G. L., Rosnagle, R. S., and Rauschkolb, E. W. Increased aldosterone secretion in response to blood loss. Circ. Res. 1956, 4, 606.

42. Laragh, J. H., and Stoerk, H. C. On the mechanism of secretion of the sodium-retaining hormone (aldosterone) within the body (abstract). J. clin. Invest. 1955, 34, 913.

43. Danowski, T. S., Elkinton, J. R., and Winkler, A. W. Movements of body water in response to acute blood loss. Amer. J. Physiol. 1946, 147, 306.

44. Welt, L. G., and Orloff, J. The effects of an increase in plasma volume on the metabolism and excretion of water and electrolytes by normal subjects. J. clin. Invest. 1951, 30, 751.

45. Lusk, J. A., Viar, W. N., and Harrison, T. R. Further studies on the effects of changes in the distribution of extracellular fluid on sodium excretion: Observations following compression of the legs. Circulation 1952, 6, 911. 